\title{
DEL IMPRESCINDIBLE CAMBIO DE MODELO CIVILIZADO
}

\author{
Luis Tamayo Pérez \\ Universidad Autónoma de Querétaro, México
}

https://doi.org/10.33676/EMUI_nomads.56.12

Resumen: Si la humanidad pretende existir más allá del presente siglo es necesario que cambie su modelo civilizatorio: el calentamiento global antropogénico y la contaminación generalizada la ponen en grave riesgo y no se aprecia que se esté generando la conciencia planetaria que permitiría mitigar tales fenómenos. Consideramos necesario plantear otro modelo civilizatorio, uno que promúeva la máxima autonomía y solidaridad para afrontar ese enorme reto.

Palabras clave: Calentamiento Global Antropogénico, Educación, Prospectiva, Biomímesis, Detección de quórum.

\section{The immediate change of the civilized model}

Abstract: If Humanity pretends to exist beyond this century is necessary to change their civilization model: Mankind is at serious risk due to anthropogenic global warming and widespread pollution and it is not appreciated that humanity is generating the planetary consciousness that would allow mitigating the phenomenon. We consider it necessary to propose another civilizing model, one that promotes the maximum autonomy and solidarity to face this enormous challenge.

Keywords: Global Anthropogenic Warming, Education, Prospective, Biomimicry, Quorum sensing.

\section{Introducción}

Según el Informe Especial sobre el calentamiento global de 1.5 grados presentado por el Panel Intergubernamental sobre Cambio Climático (IPCC por sus siglas en inglés) el 7 de octubre del 2018 en Incheon, Corea del Sur, ' las consecuencias y costos de no realizar las acciones necesarias para mitigar el Cambio climático serán mucho más graves que los referidos en la COP de Paris (2015). Podrían alcanzarse dos grados Celsius más (respecto a épocas preindustriales) antes del 2040 y, llegado a ese punto, las peores consecuencias del fenómeno serán inerciales. Es ahora más que

\footnotetext{
1 Leahy, S., (2018), National geographic, Octubre.
} 
evidente que si la humanidad pretende existir más allá del Siglo XXI es menester que cambie su modelo civilizatorio: el modelo denominado como business as usual por el IPCC (el cual implica el uso desmesurado de combustibles fósiles, revolución industrial, práctica generalizada del comprar y tirar, así como la creencia de que se cuenta con recursos infinitos en un planeta finito) que en nuestros días domina el mundo globalizado, no sólo, indica la WWF, 2 ha aniquilado a la enorme mayoría de las especies de la tierra ${ }^{3}$ sino amenaza con producir la Sexta extinción masiva de las especies hacia final de siglo. ${ }^{4}$ El punto de no retorno respecto al Calentamiento global antropogénico se encuentra mucho mas cercano de lo que quisiéramos reconocer, y cuando se alcance, seremos incapaces de detener el incremento de la temperatura de la tierra.

Hace apenas unos meses, la EASAC 5 , una agencia europea dedicada a monítorear la situación ambiental de su región y el mundo, publicó un informe donde deja claro que para tal grupo de academias ya no hay duda alguna: el calentamiento global antropogénico ha generado un incremento sostenido de los fenómenos hidrometeorológicos: las inundaciones europeas se han cuadruplicado desde 1980 y casi lo mismo ha ocurrido con las ondas de calor y los incendios forestales. Y si ampliamos la escala nos encontramos con que en el resto del planeta la situación no es diferente; se han incrementado las sequías, inundaciones, ondas de calor y demás, todo ello ocasionando un incremento creciente de refugiados ambientales, los cuales ya desestabilizan naciones -el caso de Siria- y no tardarán en propagar el malestar a prácticamente todo el globo.

Los escapes de metano del Ártico también incrementan su frecuencia e intensidad e incluso la corriente del golfo (Gulf Stream) podría ver modificadas las condiciones que la hacen posible -un delicado equilibrio entre la salinidad de las aguas oceánicas y las provenientes del derretimiento del agua dulce de Groenlandia, la tundra siberiana y el Ártico- con una grave y espantosa consecuencia: la ocurrencia de un descenso significativo y constante en la temperatura de las naciones más septentrionales de la tierra (una glaciación). Y estos datos terribles se agravan con la crisis de la ex-central nuclear de Fúkushima pues de sus ruinas escapan 300 toneladas de basura radioactiva diariamente... las

\footnotetext{
2 Siglas en inglés de la Fundación para la vida silvestre.

${ }^{3}$ Cfr. World Wildlife Fund (WWF), Informe Planeta vivo 2016:

http://d2ouvy59p0dg6k.cloudfront.net/downloads/informe_planeta_vivo_2016_2.pdf

${ }^{4}$ Kolbert, E., (2014), The Sixth Extintion, Henry Holt \& Company, NY.

5 Siglas en inglés del Consejo Consultivo de las Academias de Ciencias Europeas.
} 
cuales, en nuestros días, ha contaminado prácticamente todas las pesquerías del Océano pacífico. ${ }^{6}$

El informe de la EASAC indica también que las consecuencias de la falta de conciencia ambiental humana serán muy costosas: por poner sólo un ejemplo, las pérdidas económicas derivadas de las tormentas jse han duplicado en sólo 35 años! 7 El economista inglés Nicholas Stern ${ }^{8}$ no se equivocaba: mientras más se tarde la humanidad en responder con eficacia al fenómeno del calentamiento global antropogénico más dinero gastarán las naciones para mitigarlo... si es que logramos hacerlo pues por tratarse de un fenómeno que ataca los fundamentos fisicoquímicos del sistema tierra, cuando se supere el tipping point (el punto de no retorno), los cambios serán inerciales y por más que la especie humana intente detener el problema será incapaz de hacerlo.

La humanidad necesita cambiar su modelo civilizatorio pero... ¿ de qué manera?

\section{Del necesario cambio}

De Heráclito aprendimos que todo cambia... ${ }^{9}$ pero ese cambio no se realiza en la dirección que deseamos, simplemente avanza en relación directa con los acontecimientos históricos, tanto naturales como sociales. Dicho en términos nietzscheanos, es la voluntad de poder (Wille zur Macht) la que determina lo que ocurre en el mundo, y ella sobrepasa, con mucho, a la voluntad de los individuos.

De Aristóteles a Hegel, la filosofía reconoce el papel de mero espectador que tiene el filósofo. ${ }^{10}$

6 En octubre del 2016 la NOAA presentó imágenes que mostraron que la contaminación derivada de la catástrofe nuclear de Fukushima -ocurrida el 11 de marzo de 2011- habían alcanzado toda la costa americana, lo cual ha extinguido a varias especies de estrellas de mar canadienses y norteamericanas así como generado muerte masiva de sardinas y otras especies y ya afecta a toda la pesquería de la región. Cfr. Durden, T. (2016) Fukushima radiation has contaminated the entire Pacific Ocean:

http://www.zerohedge.com/news/2016-10-02/fukushima-radiation-has-contaminatedentire-pacific-ocean-and-its-going-get-worse

7 EASAC, 2018, p. 9ss

8 Cfr. el Informe Stern:

http://www.ambientum.com/documentos/general/resumeninformestern.pdf

9 Heráclito, Fragmento 91.

10 Al respecto basta sólo recordar la manera como Aristóteles, en el Vol. X de su Ética Nicomaquea define al filósofo como un mero "contemplador" o GWF Hegel, en las primeras páginas de su Filosofía del derecho indica que "el búho de Minerva levanta el vuelo al atardecer", es decir, cuando el día ya ha pasado. 
Existen, sin embargo, otras disciplinas —como el psicoanálisis- donde la tarea del terapeuta es precisamente la de generar cambios, pero ello ocurre de manera individual y siguiendo un complicado proceso, el cual describe Lacan en su ensayo "El tiempo lógico y el aserto de certidumbre anticipada" y que estudiaremos más adelante. Cambiar a una sociedad siguiendo ese modelo requeriría una cantidad enorme de "escansiones suspensivas" así como de un cercanía e identidad entre los humanos que no estoy seguro poseamos.

La opción de que contásemos con los cambios generados por un buen Leviatán, un tirano que, desde el poder religioso o secular, obligase a la humanidad toda a encaminarse en la dirección de su supervivencia, se aprecia simplemente imposible a causa de que los verdaderos gobernantes de la tierra ya no son los prelados, reyes o cancilleres. Los que gobiernan verdaderamente la tierra son las grandes corporaciones que, según indican Vitali, Glattfelder y Battiston, " controlan la casi totalidad del capital mundial. La voluntad individual es increíblemente pequeña en comparación con el enorme poder que despliegan esas corporaciones, las cuales son, como el caso de la farmacéutica Pfizer, 45 veces más grande que ¡el gobierno de España!12

\section{Un fallido, desesperado e incorrecto intento de revertir la situación}

La situación actual de la humanidad es en nuestros días tan grave que los pedagogos asociados al Panel Intergubernamental sobre Cambio Climático (IPCC) se han dado a la tarea de elaborar un manual para que pueda hacerse comprensible el fenómeno del Calentamiento global antropogénico (CGA) a una humanidad incapaz de hacerlo. ${ }^{13} \mathrm{~A}$ pesar de la buenas intenciones, no auguramos mucho éxito a dicho manual, pues fue realizado siguiendo un modelo equivocado -pedagógica y filosóficamente equivocado- pues considera que el ser humano es racional $y$, en consecuencia, después de entender el riesgo que implica el Calentamiento global que dicho documento presenta, actuará en consecuencia y logrará revertir el problema. Los autores de tal documento siguen pensando como Aristóteles y parecen desconocer todo lo sostenido por Freud, Lacan e innumerables psicoanalistas y filósofos, los cuales desde hace siglos muestran la ominosa irracionalidad que caracteriza a la especie humana.

\footnotetext{
11 Vide infra el apartado Las corporaciones: gobernantes ciegos de la tierra.

12 Cfr. Bakan, 2005.

13 Intergovernmental Panel on Climate Change (IPCC), (2018), Principles for effective communication and public engagement on climate change. A Handbook for IPCC authors, Climate Outreach, January, 2018.
} 
Pero avancemos lentamente y revisemos primero los planteamientos centrales del documento del IPCC.

En primer lugar, el documento reconoce el fracaso del IPCC en su intento de alertar a la humanidad respecto al fenómeno del CGA: "Como indican varias décadas de intentos de despertar la consciencia, el cambio climático no se transmite por sí mismo". "Para algunos el tópico parece abstracto e intangible, para otros las estadísticas abstractas son demasiado alejadas de su vivencia cotidiana". "En algunas naciones el tema se ha politizado. En otras lo que falta es discurso político sobre el tema". 14

Y para resolver el problema -que para los autores del documento es simplemente de comunicación- proponen a los científicos seis elementos para hacer efectivo su discurso en la transmisión del fenómeno del calentamiento global:

- Sé un comunicador confiable, es decir, aprovecha el hecho de que los científicos gozan de un gran reconocimiento social.

- Habla del mundo real, no de ideas abstractas, es decir, por ejemplo, evita el tema de las concentraciones de Gases de Efecto Invernadero (GEI) y habla de temas concretos.

- Conecta con los temas que importan a tu auditorio, es decir, de la manera como el CGA afecta a la comunidad donde se imparte la conferencia.

- Cuenta una historia humana, no hablen de estadísticas sino de lo que ocurre a los seres humanos concretos.

- Céntrate en las certezas, es decir, si bien al hablar con los científicos es muy importante tratar sobre las incertidumbres, ello puede ser difícil de tragar para los no-científicos, es por ello que debe hablarse con la población común de las certezas y enfatizar el acuerdo generalizado que tienen.

- Usa la mejor comunicación visual: una buena imagen es mejor mientras más convincente y clara sea para el público. ${ }^{15}$

Recomienda también encuadrar (to frame) lo más convenientemente posible la explicación al público objetivo, es decir que, dependiendo del público, puede ser mejor encuadrar la conveniencia del uso del los sistemas fotovoltaicos por su valor ambiental (reducción de la huella de

\footnotetext{
14 IPCC, 2018, p. 3.

15 IPCC, 2018, p. 5.
} 
carbono) o por el económico (su rentabilidad de mediano plazo).16

Asimismo, recomienda el uso de metáforas y analogías para lograr que el público comprenda el fenómeno y presenta múltiples ejemplos de ello (por ejemplo, proponen usar la metáfora de la "manta para atrapar calor" para explicar el efecto de los GEl en la atmósfera). ${ }^{17}$

En resumen, como puede apreciarse, los pedagogos autores del documento referido consideran que el problema de la falta de una respuesta efectiva de la humanidad ante el fenómeno del CGA es simplemente la falta de conocimiento preciso y que, al obtenerlo, la conducta incorrecta simplemente cambiará por añadidura.

Sinceramente nos encantaría que la cuestión se resolviese de manera tan simple: que una vez que las masas escuchen correctamente planteado el problema harán lo conveniente para resolverlo.

Desgraciadamente, más cien años de experiencia psicoanalítica demuestran lo contrario: las personas no cambian porque hayan "entendido" las razones de sus problemas. Es cierto que la historia muestra que los pueblos y sus ciudadanos "cambian"... pero cuando ello pasa lo hacen de una manera no-racional y siguiendo un modelo descrito por Jacques Lacan en su estudio "El tiempo lógico y el aserto de certidumbre anticipada". ${ }^{18}$ En dicho ensayo, el psicoanalista indica que la realización de un acto (que produce un "cambio de estado") requiere de tres momentos: el "instante de la mirada" -aquél en el cual se aprecia la situación, el problema-, el "tiempo para comprender" -el cual implica una larga o mediana serie de reflexiones sobre el asunto a decidir- y el "momento de concluir", ese que resuelve, en un acto, el problema inicial.19

En tal ensayo, Lacan muestra también que no hay una conexión lógica entre el "tiempo para comprender" y el "momento de concluir", es decir, que lo que se decide -la conclusión- no deriva directa y lógicamente de lo reflexionado en el "tiempo para comprender". 20

El acto mediante el cual alguien "cambia" es lo que lo produce como "sujeto", uno que se muestra "libre" por actuar de acuerdo a lo determinado por su "tradición heredada". ${ }^{21}$ Un cambio que deriva, indica Lacan, de una serie de "escanciones suspensivas", es decir, de momentos

\footnotetext{
16 IPCC, 2018, p. 8.

17 IPCC, 2018, p. 10.

18 Lacan, 1966.

19 Cfr. Tamayo, 1989, pp. 70ss.

20 Cfr. Allouch, 2001.

${ }^{21}$ Me refiero, obviamente, a la manera heideggeriana de concebir la libertad, Cfr. Tamayo 2001, Cap. 2.
} 
en los cuales el sujeto detiene su acción al observar la manera como actúan quienes se encuentran en su entorno. Sólo después de realizar el número necesario de "escanciones suspensivas" (que no es sino el número de los integrantes del grupo menos uno) es que puede actuarse $y$ constituirse por ende un sujeto. $Y$ el número de tales escanciones, permítanme reiterarlo, es casi tan grande como el número de actores involucrados en el acto de ese sujeto. Es este elemento el que hace tan complicada la realización de actos en pro del medioambiente en las democracias: una asamblea de 400 integrantes requeriría, para tomar una decisión bien consensuada ide 399 escanciones suspensivas!

Cuando en una nación hay sólo un sujeto tomador de decisiones (como en la monarquía absoluta), la realización de los actos es relativamente simple: obedecen a la voluntad del rey. Aunque, en tal caso, los cambios son válidos solamente mientras existe dicho rey. No son pocos los ejemplos históricos que muestran la casi total aniquilación de las medidas (tanto las buenas como las malas para la comunidad) cuando ocurre la desaparición del tirano que las impuso. ${ }^{22}$

En las democracias es mucho más difícil realizar actos pues implican el consenso y eso no es sencillo de construir (requiere de las ya mencionadas "escaciones suspensivas")... aunque su duración es mucho mayor pues son la consecuencia de la voluntad de una comunidad, no sólo de la de un tirano. Lograr esos consensos, esos acuerdos democráticos, es complicado, pero cuando se logran es magnífico... ¿ tendremos como humanidad el tiempo para hacerlo? Y sobretodo: ¿está encaminándose la humanidad en esa dirección? Eso no se aprecia con claridad en nuestro país. La nación mexicana se encuentra sometida, desde hace ya varias décadas, a un proceso que no podemos denominar sino como "estupidización generalizada". Tal estupidización se traduce no sólo en deportes televisados y telenovelas sino en adicciones, religiones y demás formas del "entretenimiento". ${ }^{23}$ Como las drogas -tanto las permitidas como las prohibidas-, los modernos gadgets electrónicos han logrado que la humanidad pase más tiempo preocupada por mirar y escuchar la pantallita de su teléfono celular que por lo que ocurre en su ciudad, en su región, en su planeta. No importa que los alimentos sean de pésima calidad y se encuentren contaminados con hormonas y pesticidas, no importa que el $\mathrm{CO} 2$, los $\mathrm{NOx}$, SOx y el $\mathrm{CH} 4$ incrementen la temperatura de

\footnotetext{
22 Como muestra basta un botón: Akenatón (https://www.bbc.com/mundo/noticias40499072).

23 Llamo "entretenimiento" a todas aquellas actividades encaminadas, como el nombre los indica, a "entretener", a mantener ocupada a la persona en actividades que no buscan resolver problema concreto alguno y sólo la mantienen atada a una pantalla o a una creencia y esperando por ello un reconocimiento, un título o una indulgencia.
} 
la tierra o que los recursos del planeta se agoten como consecuencia de la actividad extractiva que requieren las grandes corporaciones para ofrecernos sus innecesarios productos -comenzando con las joyas de oro y plata, las piedras "preciosas" y demás productos francamente innecesarios que inundan nuestras casas y no tardan mucho tiempo en convertirse en lo que siempre fueron: basura. Para el ciudadano promedio lo único importante es tener la panza Hena y la pantallita prendida para poder bajar la canción de moda y mirar la última videobroma. Esta es, triste y vergonzosamente, ta situación a la que ha llegado esa especie a la que alguna vez llamamos "sapiens sapiens" y que orgullosamente, siguiendo las tesis de Aristóteles, llegamos a denominar "animal racional". Uno que ni siquiera se da cuenta como está siendo manipulado por el mundo corporativo.

\section{Las grades corporaciones: gobernantes ciegos de la tierra}

Es evidente que en esta época existen fuerzas interesadas en mantener el estado de cosas existente (la estupidización generalizada). Y el modelo "business as usual" que el Panel Intergubernamental sobre Cambio Climático ha denunciado como aquél que extinguirá a la humanidad está sostenido por los seres humanos más poderosos del planeta, aquellos enriquecidos por sus corporaciones, aquellos que han impuesto el modelo neoliberal en todo el globo y que, gracias a la revolución industrial, consumen los agotables recursos de la tierra y esparcen la contaminación incluso en nuestros cuerpos: en nuestros días es prácticamente imposible encontrar, en nuestro mundo, un ser humano libre de plomo, mercurio, plástico y otros productos derivados de la revolución industrial. ${ }^{24}$

Como bien denuncian Braungart y MacDonough (2003), la revolución industrial ha sido una de las peores ocurrencias de la especie humana pues si bien aportó bienes y servicios asequibles a cantidades crecientes de la población, ha inundado de basura el mundo y creado cantidades crecientes de nuevas y enloquecidas "necesidades" en una población incapaz de autolimitarse. La revolución industrial y las corporaciones que se han enriquecido gracias a ella son el primer y principal oponente al cambio de modelo civilizatorio. Tales corporaciones son capaces de corromper gobiernos, modificar leyes y mentir y engañar a todos con tal de continuar obteniendo sus jugosas "ganancias"... y si el planeta entero y la

24 Braungart, M; McDonougn (2003). 
humanidad se ve destruida por su conducta... ¡lástima por ellos! Sería "un signo de su vergonzosa debilidad", Trump dixit. 25

Tal como informó el estudio "La red corporativa global" de Vitali, Glattfelder y Battiston, 26 los gobernantes del mundo son 147 grandes corporaciones a las cuales todos enriquecemos cotidianamente. Y tales corporaciones, con el apoyo de la publicidad, 27 se han poco a poco apoderado de los recursos de toda la tierra, corrompen gobiernos y solamente están preocupadas por el incremento de las ganancias de sus accionistas. Tales corporaciones no sólo consideran posible lo imposible -el crecimiento infinito y la infinitud de los recursos de la tierra- sino que son capaces de agotar los recursos naturales sólo para incrementar sus ganancias. Y tales corporaciones no actúan solas, necesitan cómplices. Sus cómplices no son sólo los funcionarios que, a lo largo y ancho de la tierra, se ven beneficiados al otorgar los permisos de operación a tal o cual corporación, lo somos también todos los que adquirimos sus contaminantes productos: cada vez que adquirimos artículos de oro somos cómplices de las empresas mineras que, empleando la técnica del tajo a cielo abierto, contaminan con cianuro y metales pesados los acuíferos del planeta; cada vez que compramos diamantes somos cómplices de los funcionarios que esclavizan a su propio pueblo para venderlos a las empresas que los extraen para luego tallarlos y comercializarlos; cada vez que adquirimos un refresco azucarado somos cómplices del imparable incremento de la diabetes y la obesidad en el mundo que las empresas refresqueras, con conocimiento de causa, promueven; cada vez que adquirimos drogas por diversión hacemos el juego a la gran corporación global del narco, esa que controla gobiernos, asesina ciudadanos y sojuzga poblaciones enteras; cada vez que adquirimos una botellita de agua nos hacemos cómplices de las grandes corporaciones que poco a poco se apropian del vital recurso en toda la tierra... por sólo mencionar unos cuantos ejemplos.

Tales corporaciones neoliberales son los verdaderos gobernantes de la tierra y ejercen su poder corrompiendo a los gobiernos para imponer sus leyes, obtener canonjías y permisos de explotación por sobre el derecho de los pueblos y dañando a la tierra y sus ecosistemas... y al adquirir sus productos nos convierten en sus cómplices.

\footnotetext{
${ }_{25}$ Me refiero a la multicitada frase que Donald Trump escribe en su libro The art of the deal (1987): "a veces parte de alcanzar un acuerdo consiste en denigrar a tus competidores": https://elpais.com/internacional/2017/06/16/universo_trump/1497632830_042916.html

26 Según los investigadores de la Universidad de Zürich: Vitali, Glattfelder y Battiston (2011), sólo 147 corporaciones transnacionales (de 43,060 estudiadas) hiperconectadas, principalmente financieras y minero-extractivas, son dueñas del $40 \%$ del PIB mundial... y 700 corporaciones son dueñas idel $80 \%$ !

27 Cfr. el ensayo No logo de Naomi Klein (2002).
} 


\section{Deshaciendo el nudo gordiano}

¿Es imposible entonces cambiar la situación? ¿̇Estamos condenados a la catástrofe?

No necesariamente. Pero para lograr el cambio que necesitamos, como nos ha enseñado Janine Benyus, ${ }^{28}$ es menester recurrir a las enseñanzas de nuestra máxima maestra: la naturaleza.

\section{Aprendiendo de las bacterias y de Buckminster Fuller}

Son esos antiguos y pequeñísimos organismos denominados bacterias los que pueden entregarnos el conocimiento respecto a como cambiar el estado actual de cosas: las bacterias son capaces de producir "cambios de estado".

Son las bacterias las que pueden, por ejemplo, cambiarnos de "vivos" a "muertos" gracias a un curioso procedimiento que Miller y Bassler (2001) denominan el Quorum sensing (Detección de Quórum).29

En su estudio sobre el Quorum sensing, Miller y Bassler nos muestran que, para cambiar un estado de cosas, las bacterias operan de la siguiente manera:

- Primero ingresan al organismo huésped, poco a poco, pasando desapercibidas...

- Es entonces cuando se multiplican y, de vez en cuando, se comunican emitiendo señales químicas en un lenguaje privado ${ }^{30} \mathrm{con}$ el objetivo de conocer su número (tanto de las bacterias de la propia especie como de las demás)...

- Y cuando detectan que son suficientes (gracias a la "detección de quórum") para actuar con eficiencia y así modificar el estado de cosas existente, actúan todas de manera coordinada, logrando el cambio de estado del organismo huésped (de sano a enfermo, por ejemplo).

\footnotetext{
28 Benyus, 2012.

29 Miller y Bassler (2001) denominan "Detección de quórum" a un procedimiento mediante el cual las bacterias, gracias a una señales químicas denominadas "autoinductores" perciben la concentración de ellas en el fluido en el cual se encuentran por lo que "La detección de un umbral mínimo de concentración estimulante de un autoinductor conduce a una alteración en la expresión génica."

30 Las bacterias Gram-negativas utilizan como autoinductores a las acil-homoserina lactonas y las Gram-positivas usan oligopéptidos procesados (Miller y Bassler, 2001).
} 
Una bacteria sola no puede hacer nada contra un organismo compuesto de millones de células, pero gracias a su estrategia, a su acción coordinada, son capaces de jacabar con nosotros!

Nosotros, operando biomiméticamente, podemos imitar su procedimiento, pero para lograrlo debemos antes despojarnos del ese narcisismo exacerbado que nos hace creernos únicos y "dueños de ideas y propiedades". Las bacterias logran sus objetivos gracias a que carecen de "derechos de propiedad" -incluida la "intelectual"- y a que priorizan la prevalencia de su especie sobre la individual.

Las bacterias nos enseñan que si somos capaces de coordinarnos aquellos que compartimos una misma manera de entender el mundo y lo hacemos primero de manera silenciosa, compartiendo y buscando adeptos, lograremos, cuando nuestro número sea suficiente, cambiar el estado de cosas existente y evitar la destrucción de nuestra civilización. Y, para lograrlo es necesario hacer religio, ser uno con el otro y el mundo, eso que nuestros pueblos originarios expresan, entre otras prácticas, mediante el tequio. ${ }^{31}$

Acorde con ello, Buckminster Fuller, un verdadero genio nacido el siglo pasado en los USA, nos dirigió la siguiente frase:

You never change things by fighting the existing reality. To change something, build a new model that makes the existing model obsolete. 32

Tal afirmación no es demasiado diferente de la que operaron los bolcheviques -y que Trotsky teoriza en sus Lecciones de octubre-para producir la revolución soviética: el entrismo. Indica Trotsky que no es necesario, para generar una revolución, que todos y cada uno de los integrantes de una sociedad estén plenamente convencidos de las bondades del nuevo modelo, basta con que un pequeño, pero convencido e influyente, número de ciudadanos -los "entristas"- lo esté. Es imprescindible, eso sí, que dichas "células revolucionarias" se encuentren bien insertadas en los diversos grupos ciudadanos, en aquellos que, por su grado de marginación o desprotección, son más proclives a apoyar movimientos que pretendan generar un cambio del estado actual de cosas.

\footnotetext{
${ }^{31}$ El tequio es una práctica de los pueblos de Mesoamérica mediante la cual los habitantes de una comunidad se obligan a la solidaridad con sus congéneres: tanto en la recolección de las cosechas como en la construcción de edificaciones para el bien común e incluso del personal.

32 Nunca cambiarás las cosas peleando contra la realidad existente. Para cambiar algo, crea un nuevo modelo que haga obsoleto al actualmente existente (Cit por Sieden, 2011: 358).
} 
Así lo hicieron, y de manera exitosa, en Rusia... aunque no sin sufrir una guerra fratricida.

Volviendo al modelo de Fuller, el cambio de modelo civilizatorio podría lograrse sin derramar sangre realizando los pasos siguientes:

- Soñar y diseñar el modelo (la utopía).

- Criticar el modelo actual a escala limitada en un diálogo crítico con amigos (manteniendo un "bajo perfil").

- Simbolizar: dar nombre tanto al monstruo como a la solución (el modelo).

- Construir el modelo alternativo (el cual se mejorará durante todo el proceso en términos de calidad y eficiencia).

- Exigir que sus componentes posean propiedad intelectual abierta (la naturaleza carece de propiedad intelectual).

- Involucrar al pequeño empresariado en la construcción de las diversas partes del nuevo modelo.

- Hacer público el nuevo modelo por todos los medios: primero en una ciudad, luego en una región, después en todo el país y el mundo.

- Hacer la mercadotecnia para crear la necesidad "no todos pueden poseerlo"). El animal humano es proclive a los engaños de la mercadotecnia. En el primer momento no podemos sino aprovecharnos de eso.

- Exigir que la Ley permita su uso.

- Conseguir que las compañías de servicios y seguros lo incluyan.

- Si es posible, enlazarlo con la identidad y el orgullo: es la "solución mexicana".

- Apoyar a la industria asociada en su producción desde las escuelas técnicas: generar muchos y muy buenos técnicos, tanto constructores como reparadores de los componentes de nuevo modelo.

- Presumir que esa industria genera muchos y buenos empleos.

- Apoyar la reducción del precio del nuevo modelo gracias a la producción masiva que lo haga accesible para todos.

- Al final, exigir que la ley corone el triunfo y prohíba los principales elementos del modelo civilizatorio anterior. 33

\footnotetext{
${ }^{33}$ Al respecto me permito citar la brillante frase de Ray Anderson, CEO de la empresa Interface, quien, en el documental The corporation (Mark Achbar; Jennifer Abbott,
} 
En resumen, si somos capaces primero de soñar y después de crear un modelo civilizatorio nuevo, seremos capaces de, si nos permitimos comenzar a vivir el mundo que soñamos, cambiar el estado de cosas existente.

\section{Conclusiones}

Cambiar el modelo civilizatorio, por tanto, requiere de un grupo ciudadano consciente y participativo, de transmisores plenamente convencidos y capaces de vivir en el nuevo modelo, los cuales, habiendo primero soñado la utopía, se hayan lanzado a realizarla en ellos mismos. El cambio requiere de ciudadanos para quienes sea claro que el ser humano que pretenda sobrevivir a la crisis venidera no podrá carecer de dos virtudes: la capacidad de convivialidad y la autonomía. Coloco primero la cualidad de convivialidad pues considero imposible que la supervivencia pueda lograrse en soledad: la unidad con el otro y la solidaridad con él son el elemento básico inicial. Es también imprescindible crear comunidades sustentables y por ende capaces de la máxima autonomía: en captación de agua de lluvia y manejo adecuado de residuos líquidos y sólidos, en la producción orgánica de alimentos, en la generación de electricidad mediante fuentes renovables, en la capacidad de curación de las enfermedades mediante fitoterapia, en la capacidad de producción de bienes y servicios de la manera más sencilla, eficiente, sustentable y bella. Solo los seres humanos dotados de tales capacidades podrán proponer un modelo que conserve lo mejor de nuestra civilización y transmitirlo a las generaciones futuras, esas que lograrán sobrevivir los peores años de la crisis derivada del Calentamiento global. Aunque, nunca lo olvidemos, eso sólo podrá lograrse a cabalidad en las comunidades ecosocialistas. ${ }^{34}$

Querétaro, México, 15 de enero de 2019

Canada, 2003) sostiene: "Un día me di cuenta de que la manera como había dirigido la empresa Interface era la de un saqueador, saqueando cosas que no me pertenecían, que pertenecían a todas las especies de la tierra. Y me dije: Dios mío, debe llegar el día en que esto sea ilegal y no permitan mas saqueos [...], algún día, la gente como yo terminará en la cárcel".

34 Al respecto Cfr. Riechmann, 2012. 


\section{Bibliografía}

- $\quad$ (1983) Aristóteles, Ética nicomaquea, UNAM, México.

- (2005) Bakan, J., The Corporation: The Pathological Pursuit of Profit and Power, Paperback. http://www.paolocirio.net/work/amazonnoir/amazon-noir-books/AMAZON-NOIR--

The_Corporation_The_Pathological_Pursuit_of_Profit_and_Power--By-Joel_Bakan_--0743247469.pdf

- (2003) Braungart, M; McDonough, Cradle to creadle: Remaking the Way We Make Things, North Point Press.

- (2016) Durden, T., Fukushima radiation has contaminated the entire Pacific Ocean (consultado 15 de abril 2017). http://www.zerohedge.com/news/2016-10-02/fukushima-radiation-hascontaminated-entire-pacific-ocean-and-its-going-get-worse

- (2018) EASAC (European Academies Science Advisory Center), Extreme weather events in Europe:

https://easac.eu/fileadmin/PDF_s/reports_statements/Extreme_Weather/EA SAC_Statement_Extreme_Weather_Events_March_2018_FINAL.pdf

- (1968) Hegel, GWF, Filosofía del derecho, Claridad, Bs. As.

- $\quad$ (1969) Heráclito, Fragmentos, Gredos, Madrid

- (2013) IPCC (Intergovernmental Panel on Climate Change), Fifth Assessment Report (AR5): https://www.ipcc.ch/report/ar5/syr/index_es.shtml

(2018), Principles for effective communication and public engagement on

climate change. A Handbook for IPCC authors, Climate Outreach.

- (2002) Klein, Naomi, No logo. El poder de las marcas, Paidós, Barcelona.

- (2014) Kolbert, E., The Sixth Extintion, Henry Holt \& Company, NY.

- $\quad$ (1966) Lacan, J., Écrits, Seuil, Paris.

- (2018) Leahy, S., Nuevo informe del IPCC: los efectos del cambio climático serán peores de los previsto, National geographic, Octubre 2018.

- (2001) Miller, M; Bassler, B., Quorum sensing in Bacteria, February 2001. Annual Review of Microbiology 55(1):165-99:

https://www.researchgate.net/publication/1 1802810_Quorum_Sensing_in_B acteria 
- (2005) Riechmann, J., "¿Cómo cambiar hacia sociedades sostenibles? Reflexiones sobre biomimesis y autolimitación", Isegoría 32, Instituto de Filosofía, Consejo Superior de Investigaciones Científicas, España.

(2006), Biomímesis, Los libros de la catarata, Madrid.

(2012a), El socialismo puede llegar sólo en bicicleta, Los libros de la catarata, Madrid.

- (2011) Sieden, L. S., A Fuller View - Buckminster Fuller's Vision of Hope and Abundance for all, Divine Arts Media, USA.

- (2001) Tamayo, L., Del síntoma al acto, UAQ, México.

(2004). El discipulado en la formación del psicoanalista. Un aporte del psicoanálisis a la pedagogía, Instituto de Cultura de Morelos/CIDHEM, México.

(2010), La locura ecocida, Fontamara, México.

(2017), Aprender a decrecer 2.0, El Colegio de Morelos/ULSAC, México.

- (1975) Trotsky, L., Lecciones de octubre, Juan Pablos, México.

- $\quad$ (1987) Trump, D.; Schwartz, T., The art of the deal, Random House, NY.

- $\quad$ (2011) Vitali, S., Glattfelder, J-B, Battiston, S., "The Network of Global Corporate Control" (Universidad de Zürich), Plos One, 26 de octubre.

- (2016) World Wildlife Fund (WWF), Informe Planeta vivo 2016: http://d2ouvy59p0dg6k.cloudfront.net/downloads/informe_planeta_vivo_2 016_2.pdf 